\title{
Bulk Etch Rate of LR 115 Polymeric Radon Detector
}

\author{
Dabo S. I. Agba1, Koudou Djagouri², Bogbe D. L. H. Gogon³, Aka A. Koua3 \\ ${ }^{1}$ Laboratory of Fundamental and Applied Physics, University Department of Fundamental and Applied Sciences, University \\ Nangui Abrogoua, Abidjan, Côte d'Ivoire \\ ${ }^{2}$ Normal High School, Abidjan, Côte d'Ivoire \\ ${ }^{3}$ Laboratory of Sciences of Matter, Environment and Solar Energy-Team of Nuclear Physics and Radiation Protection, University \\ Department of Sciences of Matter Structures and Technology, University Félix Houphöuet—Boigny, Abidjan, Côte d'Ivoire \\ Email: ignaceagba@yahoo.fr
}

How to cite this paper: Agba, D.S.I., Djagouri, K., Gogon, B.D.L.H. and Koua, A.A. (2021) Bulk Etch Rate of LR 115 Polymeric Radon Detector. Detection, 8, 1-8. https://doi.org/10.4236/detection.2021.81001

Received: January 16, 2021

Accepted: January 28, 2021

Published: January 31, 2021

Copyright (c) 2021 by author(s) and Scientific Research Publishing Inc. This work is licensed under the Creative Commons Attribution International License (CC BY 4.0).

http://creativecommons.org/licenses/by/4.0/

\section{cc (i) Open Access}

\begin{abstract}
In this study, we used strippable LR 115 type 2 which is a Solid State Nuclear Track Detector (SSNTD) widely known for radon gas detection and measurement. The removed thickness of the active layer of samples of this SSNTD, were determined by measuring the average initial thickness (before etching) and residual thickness after 80 to 135 minutes chemical etching in the standard conditions, using an electronic comparator. These results allowed the calculation of the bulk etch rate of this detector in a simple way. The mean value obtained is $(3.21 \pm 0.21) \mu \mathrm{m} / \mathrm{h}$. This value is in close agreement with those reported by different authors. It is an important parameter for alpha track counting on the sensitive surface of this polymeric detector after chemical etching because track density depends extremely on its removed layer. This SSNTD was then used for environmental radon gas monitoring in Côte d'Ivoire.
\end{abstract}

\section{Keywords}

Strippable LR 115 Type 2, Chemical Etching, Removed Layer, Bulk Etch Rate

\section{Introduction}

Radon, a natural radioactive and lung carcinogen gas [1] can be detected by many techniques [2] [3] [4]. The SSNTD are the most widely used detectors in this way by many researchers around the world [5] [6] and LR 115 is the best SSNTD for radon [7]. Alpha particles emitted by radon and its progeny hit the detector and left latent tracks in it. Several different techniques of track revela- 
tion are known [8] [9] [10], but, the chemical etching technique is the most frequently used. Many authors had established that the removed active layer of Solid State Nuclear Track Detector during etching is one of the main factors influencing the track parameters or shape characteristics [11] [12] [13]. Ion-track growth in SSNTD has been suggested to base on two parameters, $V_{t}$ and $V_{b}$ [14], where $V_{t}$ is the track etch rate and $V_{b}$ the bulk etch rate which is one of the most important parameters that control track formation and development and with $V_{t}$, are needed to simulate track growth and to calculate track parameters [15] [16]. The bulk etch rate is strongly related to the removed thickness of the active layer and it has been shown that $V_{b}$ depends on many factors like the purity of the basic substances, the molecular structures of polymers, conditions of polymerization, environmental conditions during the irradiation and finally on etching conditions [17]. Yip and contributors[18] showed that the bulk etch rate of LR 115 could not be controlled by temperature and etchant concentration only, and was also affected by the amount of stirring. Therefore, actual monitoring of the active layer thickness is necessary when using this detector. Various techniques were used for the determination of the bulk etch rate [18] [19] [20] [21]. Our main concern in this study is to determine in the standard etching conditions, the bulk etch rate of LR 115 type 2 by measuring the thickness of its active layer before and after chemical etching using an electronic comparator.

\section{Materials and Methods}

Commercially available, LR-115 type 2 strippable films manufactured by DOSIRAD-France, consist of an active layer or cellulose nitrate on $100 \mu \mathrm{m}$ clear polyester base. 10 pieces of this detector film (size $2 \times 2 \mathrm{~cm}$ ) were taken. The active layer of each sample was peeled off with a lancet and its thickness (initial thickness) measured on 10 different points covering its surface using an electronic comparator (Figure 1). We then deduced from the 100 measurements, the arithmetical mean of the initial thickness of LR 115 type 2 active layer.

36 other samples with the same size were irradiated with a $\mathrm{Pu}-239$ radioactive source which $\alpha$ particle emission rate in $2 \pi$ sr geometry is $3055 \alpha /$ s, through a collimator of $21.79 \mathrm{~mm}$ height (Figure 2) during 5 minutes. Then, these samples were introduced in an etching bath without stirring of $\mathrm{NaOH}$ solution with the concentration $2.5 \mathrm{~mol} / \mathrm{L}$ at the constant temperature of $60^{\circ} \mathrm{C}$. After 80 minutes, three samples were taken out from the bath, rinsed off with tap water, then put in distilled water before been dried in dry air. Five (5) minutes later, three other samples were submitted to the same process. And so on every 5 minutes until 135 minutes. After been dried, each sample was peeled off with a lancet, its residual thickness measured as for the 10 previous before etching and its removed thickness calculated using the relation:

$$
e=e_{m}-e_{r}
$$

where

$e$ is the removed active layer thickness $(\mu \mathrm{m})$; 


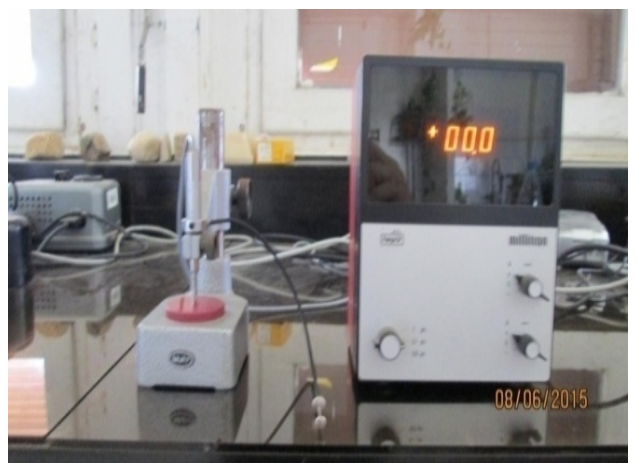

Figure 1. Electronic comparator.

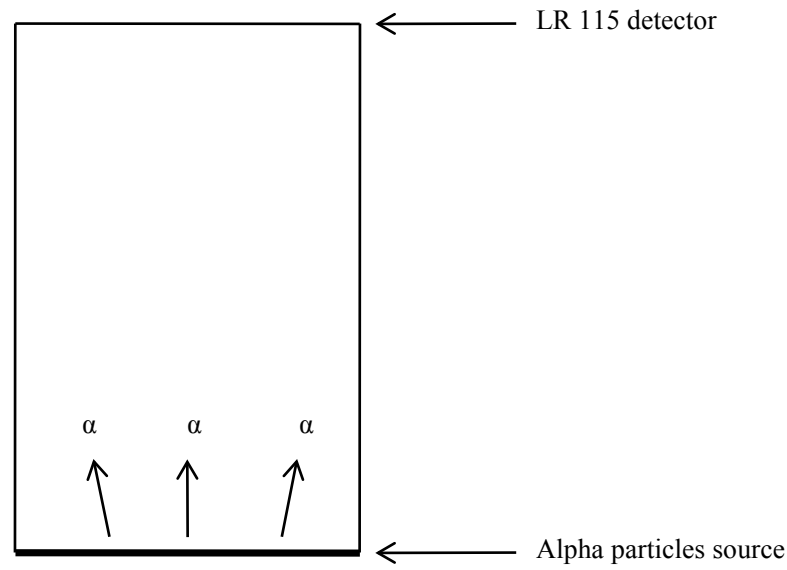

Figure 2. Schematic of irradiation system.

$e_{m}$, the mean of its initial thickness $(\mu \mathrm{m})$;

and $e_{t}$ its residual thickness $(\mu \mathrm{m})$.

Chemical etching of an irradiated SSNTD foil works on the principle that the solution preferentially attacks the damaged core of the latent track and penetrates along its length with a velocity $V_{t}$ or track etch rate while, the undamaged area of the foil is attacked at a lower rate with a velocity $V_{b}$ also called bulk etch rate. $V_{b}$ is generally constant for given etching conditions but not $V_{t}$ which depends on the amount of damage present in the region of the core. Finally the track leads to the formation of a cone with semi-cone angle $\delta$ also known as the critical angle of etching and given mathematically by:

$$
\sin \delta=\frac{V_{b}}{V_{t}}
$$

For the present experiment, we deduced the bulk etch rate of LR 115 type 2 using the formula:

$$
V_{b}=\frac{e}{t}
$$

where

$V_{b}$ is the bulk etch rate $(\mu \mathrm{m} / \mathrm{h})$;

and $t$ the etching time $(h)$. 


\section{Results and Discussion}

The arithmetical mean of the initial thickness of LR 115 type 2 active layer obtained from all the measurements is $(12.45 \pm 0.34) \mu \mathrm{m}$.

Our other experimental results are reported in the Table 1 below. Using these data, two graphs are drawn in Figure 3 and Figure 4.

In Figure 3, the thickness of the removed active layer of LR 115 type 2 increases linearly with the etching time.

According to our results, under the standard etching conditions the removed thickness obtained for $120 \mathrm{~min}$ of etching is $6.68 \mu \mathrm{m}$, and the corresponding residual thickness of the active layer is $5.77 \mu \mathrm{m}$. This last value fits well the important criteria for an optimum alpha track counting on strippable LR 115 type 2 film using a spark counter which is that the residual thickness of its active layer must range between 5.5 and $6.5 \mu \mathrm{m}$ [22].

Figure 4 shows that for etching times between 80 and 135 minutes a constant bulk etch rate was attained considering the bar errors. Its calculated arithmetical mean is $(3.21 \pm 0.21) \mu \mathrm{m} / \mathrm{h}$. This value agrees with those obtained by other authors [23] [24]. Therefore, it's possible to evaluate, with this constant value of $V_{b}$, the removed active layer thickness at any etching time using the previous equation (3).

Our calculated bulk etch rate is a little different from the value of, $3.61 \pm 0.14$ $\mu \mathrm{m} / \mathrm{h}$, obtained by Yip and contributors [18], both in the same etching conditions. The difference may be due to the fact that the initial thickness of LR 115 type 2 active layer is not exactly $12 \mu \mathrm{m}$, as usually taken for granted.

Now that $V_{b}$ was determined, it can be combined with the track etch rate $V_{t}$ to give the $\mathrm{V}$ function $\left(V=V_{t} / V_{b}\right)$, which is required for calculating track parameters [25] [26] [27]. For example, with a normally incident track, we have the following relation:

$$
D=d=2 V_{b} t \sqrt{\frac{V-1}{V+1}}
$$

where

$D$ is the major axe of the track opening;

$d$ its minor axe;

and $t$ the etching time.

In fact, the track opening being the intersection of a cone with a plane surface, the resulting shape is a conic section which is an ellipse with major axis $D$ and minor axis $d$.

For a normally incident track, $D=d$ is simply called diameter of track opening. Then, in the case of plastics like LR 115 where $V_{t}$ is very much greater than $V_{b}$ so that $V$ is very much greater than 1 , the Equation (4) gives approximately.

$$
D=d=2 V_{b} t
$$

The values of track opening diameters calculated using Equation (5) are reported in Table 2 below. 
Table 1. Removed thickness and bulk etch rate as a function of etching time.

\begin{tabular}{ccc}
\hline $\begin{array}{c}\text { Etching time } \\
(\mathrm{min})\end{array}$ & $\begin{array}{c}\text { Removed thickness } \\
(\mu \mathrm{m})\end{array}$ & $\begin{array}{c}\text { Bulk etch rate } \\
(\mu \mathrm{m} / \mathrm{h})\end{array}$ \\
\hline 80 & $3.85 \pm 0.23$ & $2.85 \pm 0.17$ \\
85 & $4.22 \pm 0.30$ & $2.97 \pm 0.21$ \\
90 & $4.37 \pm 0.29$ & $2.91 \pm 0.19$ \\
95 & $5.16 \pm 0.33$ & $3.27 \pm 0.21$ \\
100 & $5.17 \pm 0.38$ & $3.10 \pm 0.23$ \\
105 & $5.88 \pm 0.44$ & $3.36 \pm 0.25$ \\
110 & $6.22 \pm 0.40$ & $3.39 \pm 0.22$ \\
115 & $6.80 \pm 0.44$ & $3.54 \pm 0.23$ \\
120 & $6.68 \pm 0.42$ & $3.34 \pm 0.21$ \\
125 & $6.78 \pm 0.44$ & $3.26 \pm 0.21$ \\
130 & $7.12 \pm 0.54$ & $3.28 \pm 0.25$ \\
135 & $7.39 \pm 0.47$ & $3.28 \pm 0.21$ \\
\hline
\end{tabular}

Table 2. Track opening diameter as a function of etching time for a normally incident track.

\begin{tabular}{cc}
\hline $\begin{array}{c}\text { Etching time } \\
(\mathrm{min})\end{array}$ & $\begin{array}{c}\text { Track opening diameter } \\
(\mu \mathrm{m})\end{array}$ \\
80 & $7.60 \pm 0.45$ \\
85 & $8.42 \pm 0.60$ \\
90 & $8.73 \pm 0.57$ \\
95 & $10.36 \pm 0.67$ \\
100 & $10.33 \pm 0.77$ \\
105 & $11.76 \pm 0.88$ \\
110 & $12.43 \pm 0.81$ \\
115 & $13.57 \pm 0.88$ \\
120 & $13.36 \pm 0.84$ \\
125 & $13.58 \pm 0.88$ \\
130 & $14.21 \pm 1.08$ \\
135 & $14.76 \pm 0.95$ \\
\hline
\end{tabular}

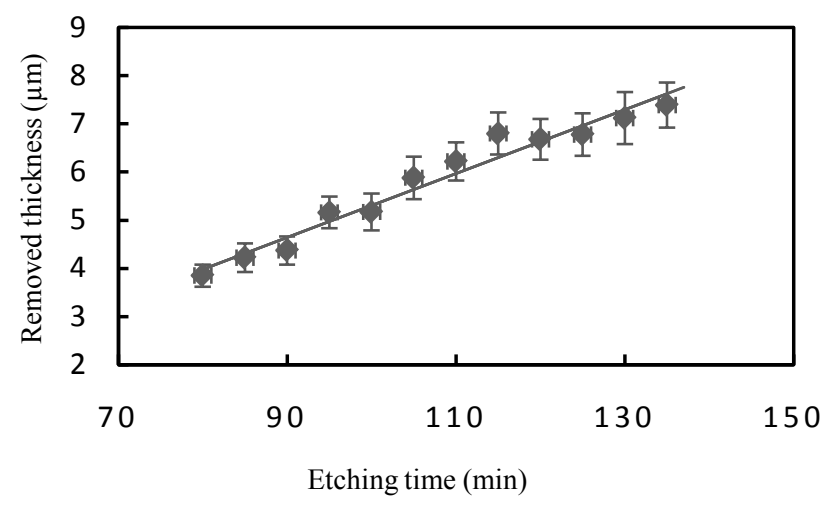

Figure 3. Removed thickness as a function of etching time. 


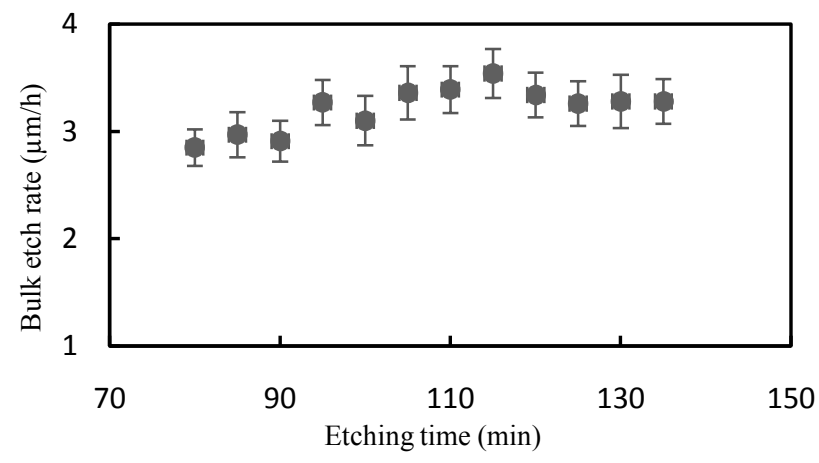

Figure 4. Bulk etch rate as a function of etching time.

\section{Conclusion}

Bulk etch rate is one of the most important factors controlling track developments in SSNTD. So, that requires precise measurement of this parameter. The result on the bulk etch rate of LR 115 type 2 film obtained under standard etching conditions without stirring during an etching time ranging between 80 and 135 minutes and using an electronic comparator is $(3.21 \pm 0.21) \mu \mathrm{m} / \mathrm{h}$. This value agrees well with those reported by other authors. Moreover, the measured thickness of the residual active layer at the etching time of 120 minutes fits well the spark counter use criteria for an optimum alpha track counting on strippable samples of this detector as it was the case for those exposed to radon gas in Côte d'Ivoire.

\section{Acknowledgements}

The authors would like to thank the International Atomic Energy Agency (IAEA) which financed this work in the frame of a Technical Cooperation among Developing Countries (TCDC) through an AFRA/RAF 0038 project entitled radon gas monitoring in Côte d'Ivoire. For their precious help, particular thanks to Dr. Z. L. Mokrani and Dr. M. Aitziane from the Department of Dosimetry and Ionizing Radiations located at the Nuclear Research Centre /Nuclear Energy Commission of Algiers (Centre de Recherche Nucléaire/Commissariat à l'Energie Atomique d'Alger (CRNA/COMENA)) where this study has been carried out.

\section{Conflicts of Interest}

The authors declare no conflicts of interest regarding the publication of this paper.

\section{References}

[1] International Agency for Research on Cancer (1988) Evaluation of Carcinogenic Risk to Humans Man-Made Mineral Fiber Sand Radon. International Agency for Research on Cancer, 43.

[2] Glenn, F.K. (1979) Radiation Detection and Measurement. John Wiley \& Sons Inc., New York. 
[3] Zeeb, H. and Shannoun, F. (2009) Who Handbook on Indoor Radon, a Public Health Perspective. World Health Organization, Geneva.

[4] Obed, R.I., Ademola, A.K. and Ogundare, F.O. (2012) Radon Measurement by Nuclear Tracks Detectors in Dwellings in Oke-Ogun Area, South-Western Nigeria. Radiation Protection Dosimetry, 148, 475-481. https://doi.org/10.1093/rpd/ncr196

[5] Lemaitre, N. (2000) A chaque cas, sa mesure. Points et Commentaires en radioprotection. Bulletin de l'office de protection contre les rayonnements ionisants, No. 9, Mars/Avril 2000.

[6] Agba, D.S.I., Koua, A.A., Dali, T.P.A., Monnehan, G.A. and Djagouri, K. (2017) Study of the Sensitivity of Polymeric Nuclear Track Detectors to Alpha Particles. Research Journal of Environmental and Earth Sciences, 2, 10-13. http://dx.doi.org/10.19026/rjees.9.5297

[7] Dwaikat, N., Safarini, G., El-hasan, M. and Iida, T. (2007) CR-39 Detector Compared with Kodalpha Film Type (LR 115) in Terms of Radon Concentration. Nuclear Instruments and Methods in Physics Research Section A, 574, 289-291. https://doi.org/10.1016/j.nima.2007.01.168

[8] Ghita, I.A. and Vasilescu, A. (2011) Radon Assessment with Solid State Nuclear Track Detectors in Bucharest and its Surrounding Region. Romanian Reports in Physics, 63, 940-947.

[9] Cosma, C., Cucos-Dinu, A., Papp, B. and Begy, R. (2003) Soil and Building Material as Main Sources of Indoor Radon in Băița-Ştei Radon Prone Area (Romania). Journal of Environmental Radioactivity, 116, 174-179.

https://doi.org/10.1016/j.jenvrad.2012.09.006

[10] Deepak, V. and Shakir Khan, M. (2014) Assessment of Indoor Radon, Thoron and Their Progeny in Dwellings of Bareilly City of Northern India Using Track Etch Detectors. Romanian Journal of Physics, 59, 172-182.

[11] Somogy, G. and Sazaly, A.S. (1973) Track-Diameter Kinetics in Dielectric Track Detectors. Nuclear Instruments and Methods, 109, 211-232. https://doi.org/10.1016/0029-554X(73)90265-6

[12] Somogy, G. (1980) Development of Etched Nuclear Tracks. Nuclear Instruments and Methods, 173, 21-42. https://doi.org/10.1016/0029-554X(80)90565-0

[13] Jonsson, G. (1981) The Angular Sensitivity of Kodak LR-115 Film to Alpha Particles. Nuclear Instruments and Methods, 190, 407-409.

[14] Fleisher, R.L., Price, P.B. and Walker, R.M. (1975) Nuclear Track in Solids: Principles and Applications. University of California Press, Berkley.

[15] Nikezic, D. and Yu, K.N. (2003) Calculations of Track Parameters and Plots of Track Openings and Wall Profiles in CR39 Detector. Radiation Measurements, 37, 595-601. https://doi.org/10.1016/S1350-4487(03)00080-5

[16] Nikezic, D., Ng, F.M.F. and Yu, K.N. (2004) Theoretical Basis for Long-Term Measurements of Equilibrium Factors Using LR 115 Detectors. Applied Radiation and Isotopes, 61, 1431-1435. https://doi.org/10.1016/j.apradiso.2004.05.065

[17] Fuji, M., Yokota, R., Atarashi, Y. and Hasegawa, H. (1991) Etching Characteristics of the New Polymeric Track Detector SR-86. International Journal of Radiation Applications and Instrumentation. Part D: Nuclear Tracks and Radiation Measurements, 19, 171-176. https://doi.org/10.1016/1359-0189(91)90167-G

[18] Yip, C.W.Y., Ho, J.P.Y., Nikezic, D. and Yu, K.N. (2003) A Fast Method to Measure the Thickness of Removed Layer from Etching of SSNTD Based on EDXRF. Radiation Measurements, 36, 161-164. https://doi.org/10.1016/S1350-4487(03)00115-X 
[19] Yu, K.N., Yip, C.W.Y., Ho, J.P.Y. and Nikezic, D. (2004) Application of Surface Profilometry in Studying the Bulk Etch of Solid State Nuclear Track Detectors, Current Issues on Multidisciplinary Microscopy Research and Education, FORMATEX, 250-256.

[20] Salama, T.A., Seddiki, U., Hegazy, T.M. and Morsy, A.A (2006) Direct Determination of Bulk Etching Rate for LR-115-11 Solid State Nuclear Track Detectors. Pramana, 67, 529-534. https://doi.org/10.1007/s12043-006-0013-1

[21] Tse, K.C.C, Ng, F.M.F, Nikezic, D. and Yu, K.N. (2007) Bulk Etch Characteristics of Colorless LR 115 SSNTD. Nuclear Instruments and Methods in Physics Research Section B: Beam Interactions with Materials and Atoms, 263, 294-299. https://doi.org/10.1016/j.nimb.2007.04.308

[22] Cross, W.G. and Tommasino, L. (1970) Rapid Reading Technique for Nuclear Particles Damage Tracks in Thin Foils. Radiation Effects, 5, 85-89.

https://doi.org/10.1080/00337577008235000

[23] Nikezic, D. and Janicijevic, A. (2002) Bulk Etching Rate of LR 115 Detectors. Applied Radiation and Isotopes, 57, 275-278.

https://doi.org/10.1016/S0969-8043(02)00109-4

[24] Nassiba, M. And Kahina, A. (2015) Mesure du gaz Radon à l'aide des Détecteurs Solides de Traces Nucléaires. Master en Physique option Biophysique et Imagerie, Université Abderrahmane Mira de Bejaïa, Béjaïa.

[25] Nikezić, D. and Kostić, D. (1997) Simulation of the Track Growth and Determination the Track Parameters. Radiation Measurements, 28, 185-190.

https://doi.org/10.1016/S1350-4487(97)00065-6

[26] Nikezic, D. (2000). Three Dimensional Analytical Determination of the Track Parameters. Radiation Measurements, 32, 277-282. https://doi.org/10.1016/S1350-4487(00)00034-2

[27] Yip, C.W.Y., Nikezic, D., Ho, J.P.Y. and Yu, K.N. (2006) Chemical Etching Characteristics for Cellulose Nitrate. Materials Chemistry and Physics, 95, 307-312. https://doi.org/10.1016/j.matchemphys.2005.06.024 